\title{
Mothers' restrictive eating and food neophobia and fathers' dietary quality are associated with breast-feeding duration and introduction of solid foods: the STEPS study
}

\author{
Jenni Vaarno ${ }^{1, *}$, Harri Niinikoski ${ }^{1,2}$, Anne Kaljonen ${ }^{1}$, Minna Aromaa ${ }^{3}$ and \\ Hanna Lagström ${ }^{1}$ \\ ${ }^{1}$ Turku Institute for Child and Youth Research, $\mathrm{Fl}-20014$ University of Turku, Finland: ${ }^{2}$ Department of Pediatrics, \\ University of Turku, Turku, Finland: ${ }^{3}$ Turku City Hospital, Outpatient Clinic for Children and Adolescents, \\ Turku, Finland
}

Submitted 6 March 2014: Final revision received 7 0ctober 2014: Accepted 15 October 2014: First published online 4 December 2014

\begin{abstract}
Objective: The purpose of the present study was to examine the association between parental eating behaviours and dietary patterns and feeding practices of infants and young children.

Design: Data on infant-feeding practices were collected from each infant's birth via parentally self-administered follow-up diaries. Three questionnaires, the ThreeFactor Eating Questionnaire, the Food Neophobia Scale and the Index of Diet Quality, were administered when the children were aged 4 and 13 months.

Setting: South-western Finland.

Subjects: Families participating in the STEPS longitudinal cohort study ( $n$ 1797).

Results: Mean duration of exclusive breast-feeding was 2.4 months and total duration of breast-feeding averaged 8.1 months. The first solid food was introduced into children's diets at the age of 3.9 months, on average. Mothers with highly restrictive eating were more likely to introduce solid foods sooner than mothers who ranked lower in these behaviours $(3.8$ months $v$. 4.0 months, $P=0.012)$. Neophobic mothers breast-fed exclusively (2.0 v. 2.6 months, $P=0.038)$ and in total $(7.2 v .8 .5$ months, $P=0.039)$ for shorter times than average mothers, even after adjusting for various demographic characteristics. Fathers' diet quality was associated with total breast-feeding duration and with introduction of complementary foods in unadjusted analyses and with total breastfeeding duration also after adjusting for confounding factors.

Conclusions: Mothers' and fathers' eating patterns and practices are associated with the feeding practices of infants and young children. Health promotion interventions seeking to improve parents' eating patterns might lead to more favourable feeding practices for infants and young children.
\end{abstract}

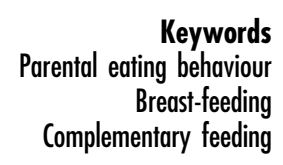

Feeding practices for infants and young children are important in order to ensure optimal growth and development in childhood, as well as health and well-being later in life. Breast milk, fed exclusively for the first 6 months and thereafter with adequate complementary foods until 1-2 years of age, is recommended globally to provide the best nutrition for infants as well as long- and short-term health benefits for the mother and child ${ }^{(1-3)}$. However, breastfeeding (BF) duration and complementary feeding practices are far from the recommended standards in many countries, including Finland ${ }^{(4-6)}$.

Infant feeding behaviour and practices are influenced by numerous factors. In particular, the determinants of BF have been widely studied. BF initiation and duration have commonly been related to maternal age, marital status, race, smoking, educational level, socio-economic status, maternal obesity, parity, method of delivery and psychosocial factors ${ }^{(7,8)}$. Furthermore, studies have reported that the introduction of solid foods earlier than recommended may also be influenced by multiple factors, such as a mother's young age, smoking, low educational level, marital status or a child's low birth weight ${ }^{(9-12)}$.

Parents' eating behaviours influence infant and young child feeding practices. Women with eating disorders tend to breast-feed for shorter periods than do women without eating disorders ${ }^{(13,14)}$. In a recent study, restrained and 
external eating behaviours in the mother, but not emotional eating behaviours, were associated with decreased likelihood of BF from birth, as well as shorter BF duration $^{(15)}$. Moreover, mothers with high restraint and external eating were more likely to feed their children based on a maternal- than an infant-led routine. Mothers high in food neophobia (an unwillingness to taste or eat unfamiliar foods or fear of these foods) were shown to give less healthy foods to their children and to impose more weight-related food restrictions ${ }^{(16)}$; however, the impact of parental food neophobia on early infant feeding has been poorly studied. Poor maternal diet, limited consumption of fruits and vegetables and a lack of time to eat healthily have all been associated with shorter BF duration and earlier initiation of complementary foods ${ }^{(17-20)}$.

In the child's infancy, the mother typically provides the majority of daily care, including feeding, but the father has an important role in supporting the mother's initiation and continuation of BF and sharing the responsibility for complementary feeding ${ }^{(21,22)}$. The relationship between fathers' eating behaviours and child-feeding practices has been studied less than that of mothers', and most of these studies have focused on school-aged children ${ }^{(23,24)}$. There seems to be a relationship between fathers and children in terms of eating certain foods; however, the effect is fairly small ${ }^{(25,26)}$.

The present study aimed to evaluate how BF duration and the introduction of complementary foods are affected by maternal and paternal eating behaviours and practices. Based on the studies mentioned earlier, we hypothesized that parents with problems controlling their own eating, especially those exhibiting restrictive or neophobic eating behaviours, would adopt controlling child-feeding practices by (i) BF for a shorter time and (ii) introducing solid foods into infants' diets earlier. We suggest that this is because complementary feeding, similarly to formula feeding, may give mothers more control over food intake than does the infant-led nature of $\mathrm{BF}^{(27)}$.

\section{Methods}

\section{Participants and procedure}

The present study is based on data from children and parents participating in a longitudinal cohort, Steps to the Healthy Development of Children (the STEPS study), which has been described in detail elsewhere ${ }^{(28)}$. The cohort population consisted of all mothers who delivered living children between 1 January 2008 and 30 April 2010 in the Hospital District of Southwest Finland, along with these mothers' children (in total, 9811 mothers and 9936 children). Of this cohort, 1797 mothers, 1827 children and 1658 partners decided to participate in the STEPS study during pregnancy at the maternity health-care clinics or after delivery at the hospitals. These are the participants in the intensive follow-up group of the STEPS study. Of the families participating in the intensive follow-up group of the
STEPS study, families who had data on exclusive and partial $\mathrm{BF}$, the introduction of complementary foods and one or more aspects of parental eating behaviours or dietary patterns were included in the present analyses. Recruitmentbased selection bias was minimized by collecting data from participants of the STEPS study, who represent the general population of mothers, fathers and children that were unselected related to feeding and eating.

Data on BF and the introduction of complementary foods were obtained in real time with a self-administered follow-up diary ( $n$ 1145). Information on cognitive restraint, uncontrolled eating and emotional eating ( $n 1066$ for mothers and $n 953$ for fathers) was collected from parents when a child involved in the STEPS study was 4 months old. Information on food neophobia ( $n 1064$ for mothers and $n 922$ for fathers) and dietary quality ( $n 1037$ for mothers and $n 848$ for fathers) was collected when a child was 13 months old. Background information on the mothers and fathers, including education, marital status, employment and familial income, were collected at the time of recruitment.

\section{Measures}

\section{Child-feeding practices}

Information about $\mathrm{BF}$ and complementary feeding were obtained via a self-administered follow-up diary. The follow-up diary consisted of detailed information about durations of exclusive BF (date started and date ended), partial BF (referred to as 'total duration of BF'; date started and date ended), the initiation of complementary feeding and information about which specific foods or food groups were given and at what age the foods were given for the first time. The records were collected in real time. Exclusive BF was defined as an infant receiving no food other than a mother's breast milk, except for water.

\section{Parental questionnaires}

The mothers and fathers completed three instruments via self-administered questionnaires measuring their eating behaviours and practices at the children's ages of 4 months and 13 months: (i) the Three-Factor Eating Revised eighteen-item Questionnaire (TFEQ-R18) ${ }^{(29)}$; (iii) the Food Neophobia Scale (FNS) ${ }^{(30)}$; and (iii) the Index of Diet Quality (IDQ) ${ }^{(31)}$.

Three characteristics of parental eating behaviour were measured using the TFEQ-R18: cognitive restraint, uncontrolled eating and emotional eating ${ }^{(29)}$. Cognitive restraint of eating refers to a person's attempts to cognitively control food intake, uncontrolled eating is the failure to restrict eating and emotional eating refers to overeating due to negative emotions. Cognitive restraint was measured with six items (e.g. 'How likely are you to consciously eat less than you want?'), uncontrolled eating with nine items (e.g. 'I am always hungry, so it is hard for me to stop eating before I finish the food on my plate') and 
emotional eating with three items (e.g. 'When I feel blue, I often overeat'). All items were coded on a 4-point scale of frequency or truthfulness of the behaviour. Higher total scores indicated more of each behaviour type. The TFEQ has mainly been used in overweight and obese individuals, but it is also valid in distinguishing eating behaviours in the general population ${ }^{(32,33)}$. Cognitive restraint, uncontrolled eating and emotional eating for each participant were recorded as either low and high behaviours, according to the median split ${ }^{(34)}$. Cronbach's $\alpha$ values for cognitive restraint, uncontrolled eating and emotional eating were $0.73,0.86$ and 0.88 , respectively, indicating reasonable internal consistency.

Parents' food neophobia was assessed using Pliner and Hobden's FNS ${ }^{(30)}$. We used the Finnish translation of the FNS validated in the Finnish adult population ${ }^{(35)}$. The FNS consists of ten statements (e.g. 'If I don't know what is in a food, I won't try it'), each rated on a 7-point scale from 'strongly disagree' (scored as 1) to 'strongly agree' (scored as 7). The responses for half of the statements worded to indicate food neophilia (e.g. 'I will eat almost anything') were reversed and the food neophobia score was calculated as a sum of the responses. The total score ranged from 10 to 65. FNS can be used as a continuous variable or to classify scores into groups regarding levels of food neophobia. In our study, we divided the participants into three groups using the 33rd and 66th percentile points as cut-off values $^{(35,36)}$. Those who scored $10-16$ were categorized as food neophilics, those who scored 17-39 were categorized as average and those who scored 40-65 were categorized as food neophobics. The Cronbach's $\alpha$ reliability for FNS was $0 \cdot 88$, the same value reported when FNS was developed ${ }^{(30)}$.

Diet was assessed using the IDQ, which was validated with $7 \mathrm{~d}$ food records and has been described in detail previously $^{(31)}$. In brief, IDQ measures adherence to healthpromoting diet and nutrition recommendations with a set of eighteen questions, resulting in a total score ranging from 0 to 15 points; the higher the points, the better the adherence to the nutrition recommendations. The IDQ consists of eighteen questions designed to measure six different aspects of diet: meal pattern and the use of vegetables, fruits and berries, sugar, wholegrain products, fat-containing products and dairy products. Six sub-scores include between one and four questions, with the potential range of maximum sub-score being 1 to 4 points. We used the IDQ score in its original form by setting the statistically defined cut-off value at 10, with scores below 10 points indicating unhealthy diets and non-adherence and scores of 10-15 points indicating a health-promoting diet and adherence to a health-promoting diet and dietary guidelines. Internal consistency, as computed by means of the Cronbach's $\alpha$ for IDQ, was $0 \cdot 43$.

\section{Confounding factors}

Analyses were adjusted for various potential confounding factors. Confounding factors used in the study were selected based on earlier studies on factors influencing infant feeding ${ }^{(7-12)}$. Information regarding marital status, biological family, total family income, number of siblings, mother's age, and mothers' and fathers' working status, education and profession were obtained from questionnaires self-administered during the prenatal period. Family income was classified into two categories: high income $(\geq 3000 € /$ month net) and low income $(<3000$ $€ /$ month net). Mothers' age was classified into two categories according to a split by the mean age of women giving birth in Finland in the year 2012. Mothers' and fathers' weights and heights were measured during their study visit when their children were about 13 months old. Heights of the parents were measured to the nearest millimetre with a Harpenden stadiometer (Holtain, Crymych, UK) and weights were measured to the nearest $0 \cdot 1 \mathrm{~kg}$ with an electronic scale (Tanita WB110MA; Tanita Corporation, Tokyo, Japan). Parents' BMI were calculated as $\mathrm{kg} / \mathrm{m}^{2}$ and classified as normal weight $\left(<25.0 \mathrm{~kg} / \mathrm{m}^{2}\right)$ and overweight $\left(\geq 25.0 \mathrm{~kg} / \mathrm{m}^{2}\right.$ ). Occupational class was classified into the following categories: (i) professionals (in high positions, e.g. managerial, but also in intermediate positions, such as nurses); and (ii) and others (blue-collar workers in industry or agriculture and service workers). Education was classified into either advanced education or low education based on the education that the parents had completed for their professions. The educational levels of those who had the highest levels of vocational training (such as a 4-year programme at a polytechnic institute) or any academic degree (bachelor's, master's, licentiate or doctoral degree) were regarded as advanced education. Information on children's birth weight, gestational age and sex were obtained from the Longitudinal Census Files; birth weight was classified according to a split at $3000 \mathrm{~g}$ and gestational age according to a split at 37 weeks.

\section{Statistical analysis}

The $t$ test for independent samples and ANOVA were used for comparison of full $\mathrm{BF}$, total duration of $\mathrm{BF}$ and the introduction of complementary foods by families', parents' and children's characteristics and parental eating behaviours. Families', parents' and children's characteristics and parental eating behaviour variables, except food neophobia, were coded as dichotomous variables. After examining these unadjusted associations, we examined potentially confounding factors and adjusted the model for the following variables: marital status; biological family; number of siblings; maternal age, BMI, occupational class and education; paternal BMI, occupational class and education; and child's sex, prematurity and birth weight. ANOVA was used to study the adjusted association between parental eating behaviour and full BF, total duration of $\mathrm{BF}$ and the introduction of complementary foods. Statistical analyses were performed using the statistical software packages SPSS version 16 and SAS 
version $9 \cdot 3$. The statistical significance was set to $P<0.05$ in all analyses.

\section{Results}

\section{General results}

The mean age of mothers at the birth of their children was 30.7 (SD 4.6) years and that of fathers was 32.7 (SD 5.5) years. The majority of mothers $(56.4 \%)$ were married to their partners at the time of enrolment. At the time of enrolment, the mean BMI for mothers was 24.3 (sD 4.8 ) $\mathrm{kg} / \mathrm{m}^{2}$ and that for fathers was $26.0(\mathrm{SD} 3.5) \mathrm{kg} / \mathrm{m}^{2}$. When the children reached 13 months, the mean BMI of mothers was $25 \cdot 2$ (SD $5 \cdot 3) \mathrm{kg} / \mathrm{m}^{2}$ and that of fathers was 26.9 (SD $3.9) \mathrm{kg} / \mathrm{m}^{2}$. The child studied was the firstborn in $53 \cdot 1 \%$ of the families and the study population included more boy children than girl children $(52.1 \% v$. 47.9\%). The mean birth weight of the children was 3502 (SD 561) g and $5.6 \%$ of the children were born preterm ( $<37$ weeks).

The mean cognitive restraint, uncontrolled eating and emotional eating scores were, respectively, 38.6, 33.4 and 36.6 for mothers and 33.0, 28.8 and 15.7 for fathers. The mothers' cognitive restraint, uncontrolled eating and emotional eating scores were significantly higher than those of the fathers $(P<0.001)$. The mean FNS score of both the mothers and the fathers was 28 (SD 11). There was no statistically significant difference between mothers' and fathers' food neophobia scores. Most mothers (54.9\%) and fathers $(70 \cdot 0 \%)$ had a total IDQ score of $0-9$ points and were thus defined as having an unhealthy diet. Mothers had significantly better diet quality than fathers $(P<0 \cdot 001)$.

Exclusive BF continued, on average, for 2.4 months, whereas the average total duration of $\mathrm{BF}$ was 8.1 months. Over half (54\%) of the children were fed with formula only or formula with breast milk at the age of introduction to complementary foods. The first solid food was introduced into children's diets at the age of 3.9 months, on average. At 5 months, $90 \%$ of infants had been introduced to at least some solid food. The first food introduced was usually potato or carrot, or sometimes cereals (e.g. corn, rice or oats).

Mothers who were married, had two or more children, had normal BMI $\left(<25.0 \mathrm{~kg} / \mathrm{m}^{2}\right)$ and who were highly educated continued exclusive $\mathrm{BF}$ and total $\mathrm{BF}$ for longer and introduced complementary foods later than did other mothers. Fathers' professional occupation and education level, as well as infant birth weight $\geq 3000 \mathrm{~g}$, were also associated with longer exclusive $\mathrm{BF}$, longer total $\mathrm{BF}$ duration and the later introduction of complementary foods. The genetic relationship or relation by marriage of all family members was associated with longer duration of exclusive $\mathrm{BF}$ and later introduction of complementary foods. Mothers who were professionals and who were older than the mean age of all women giving birth in Finland continued total BF for longer and introduced complementary foods later than younger mothers with other occupations. Further demographic details and their associations with infant feeding can be found in Table 1. No association was found between BF duration or age of introduction of complementary foods and family income or mothers' and fathers' working status.

\section{Mothers' eating behaviours and infant feeding}

Maternal cognitive restraint was significantly associated with all measured aspects of child-feeding practices (Table 2). Mothers with low cognitive restraint breast-fed their child exclusively and for a longer total time than mothers with high cognitive restraint $(P=0.029$ and $P=0.008$, respectively). The introduction of complementary foods was undertaken later by mothers with low cognitive restraint than by mothers with high cognitive restraint $(P=0.006)$. Uncontrolled eating and emotional eating did not have significant associations with childfeeding practices. After adjusting for confounding factors, high maternal cognitive restraint was found to be associated with earlier introduction of complementary foods $(F(1,442)=4.92, P=0.027$; Table 3$)$.

In the unadjusted analyses, maternal food neophobia was associated with the durations of full and total BF (Table 2). Exclusive BF duration was shortest with neophobic mothers (2.01 months), slightly longer with neophilic mothers (2.10 months) and longest with average mothers (2.55 months, $P=0.002$ ). This difference was statistically significant between average and neophobic mothers (post hoc test, $P<0.05)$ and between neophilic and average mothers (post hoc test, $P<0 \cdot 05$ ). The exclusive BF duration was significantly longer for average mothers than for neophobic or neophilic mothers, even after controlling for confounding factors $(F(2,431)=5 \cdot 00, P=0 \cdot 007$; Table 3$)$. There was no significant association between maternal neophobia and the total duration of $\mathrm{BF}$ and infant age at introduction of the first solid foods in the adjusted analyses.

Mothers' dietary quality influenced child-feeding practices in unadjusted analyses. Higher maternal IDQ points, indicating better adherence to nutritional recommendations and measured when children reached 13 months, were associated with a longer total BF duration and later introduction of complementary foods $(P=0.003$ and $P=0.027$, respectively; Table 2 ). A similar trend was seen in the duration of exclusive $\mathrm{BF}$, but the association was not significant $(P=0 \cdot 124)$. After controlling for confounding variables, maternal dietary quality had no significant association with BF duration or the introduction of complementary foods (Table 3).

\section{Fathers' eating behaviours and infant feeding}

No significant associations were found between paternal cognitive restraint, uncontrolled eating or emotional eating and child-feeding practices (Table 2). Moreover, fathers' neophobia ratings did not relate to infant-feeding practices. Children of fathers with good dietary quality were breast-fed for longer in total $(P=0.011)$ and introduced to complementary foods later $(P=0.014)$ than children of 
Table 1 Duration of exclusive breast-feeding (EBF), total duration of breast-feeding (BF) and age of introduction of complementary foods (CF) by familial, maternal, paternal and children's characteristics: STEPS longitudinal cohort study $(n 1797)$

\begin{tabular}{|c|c|c|c|c|c|c|c|c|c|c|c|c|}
\hline \multirow[b]{2}{*}{ Variable } & \multicolumn{4}{|c|}{ EBF duration (months) } & \multicolumn{4}{|c|}{ Total BF duration (months) } & \multicolumn{4}{|c|}{ Age of introduction CF (months) } \\
\hline & $n$ & Mean & SD & $P$ & $n$ & Mean & SD & $P$ & $n$ & Mean & SD & $P$ \\
\hline \multicolumn{13}{|l|}{ Family } \\
\hline \multicolumn{13}{|l|}{ Marital status } \\
\hline Married & 685 & $2 \cdot 55$ & $2 \cdot 1$ & \multirow[t]{2}{*}{$<0.001$} & 558 & 8.47 & 4.5 & \multirow[t]{2}{*}{0.011} & 688 & 4.01 & 0.9 & \multirow[t]{2}{*}{0.006} \\
\hline Not married & 434 & 2.09 & $2 \cdot 1$ & & 363 & 7.67 & 4.8 & & 438 & 3.84 & $1 \cdot 1$ & \\
\hline \multicolumn{13}{|l|}{ Biological family* } \\
\hline Yes & 955 & $2 \cdot 44$ & $2 \cdot 1$ & \multirow[t]{2}{*}{0.004} & 782 & $8 \cdot 20$ & 4.5 & \multirow[t]{2}{*}{0.483} & 962 & 3.98 & 1.0 & \multirow[t]{2}{*}{0.019} \\
\hline No & 141 & 1.94 & 1.8 & & 119 & 7.88 & $5 \cdot 7$ & & 141 & 3.76 & 1.0 & \\
\hline \multicolumn{13}{|c|}{ Number of children } \\
\hline 1 & 612 & $2 \cdot 10$ & $2 \cdot 0$ & \multirow[t]{2}{*}{$<0.001$} & 527 & 8.65 & 4.8 & \multirow[t]{2}{*}{0.004} & 610 & 3.84 & 1.0 & $<0.001$ \\
\hline$\geq 2$ & 516 & $2 \cdot 68$ & $2 \cdot 1$ & & 401 & $7 \cdot 77$ & 4.5 & & 525 & 4.07 & 1.0 & \\
\hline Family income $\dagger$ & & & & & & & & & & & & \\
\hline High income & 523 & $2 \cdot 42$ & $2 \cdot 1$ & 0.401 & 435 & 8.25 & 4.5 & 0.455 & 526 & 3.98 & 0.9 & 0.233 \\
\hline Low income & 583 & $2 \cdot 32$ & $2 \cdot 1$ & & 478 & 8.02 & 4.8 & & 586 & 3.90 & 1.0 & \\
\hline Mothers & & & & & & & & & & & & \\
\hline Age $\neq$ & & & & & & & & & & & & \\
\hline$<30.3$ years & 477 & $2 \cdot 35$ & $2 \cdot 1$ & 0.897 & 400 & $7 \cdot 79$ & 4.6 & 0.040 & 469 & $3 \cdot 86$ & 1.0 & 0.026 \\
\hline$\geq 30.3$ years & 624 & $2 \cdot 37$ & $2 \cdot 0$ & & 506 & 8.42 & 4.6 & & 639 & 4.00 & 1.0 & \\
\hline BMI status§ & & & & & & & & & & & & \\
\hline Normal weight & 635 & 2.59 & $2 \cdot 0$ & $<0.001$ & 519 & 8.93 & 4.5 & $<0.001$ & 641 & 4.03 & 0.9 & 0.003 \\
\hline Overweight & 403 & $2 \cdot 01$ & $2 \cdot 1$ & & 336 & $7 \cdot 25$ & 4.8 & & 403 & 3.84 & 1.1 & \\
\hline Working status\|l & & & & & & & & & & & & \\
\hline Working & 834 & $2 \cdot 31$ & $2 \cdot 1$ & 0.184 & 695 & $8 \cdot 26$ & 4.5 & 0.219 & 844 & 3.93 & 1.0 & 0.553 \\
\hline Not working & 281 & $2 \cdot 50$ & $2 \cdot 1$ & & 224 & 7.82 & $5 \cdot 0$ & & 278 & 3.97 & 0.9 & \\
\hline Occupational clas & & & & & & & & & & & & \\
\hline Professionals & 633 & $2 \cdot 38$ & $2 \cdot 1$ & 0.257 & 526 & 8.63 & 4.4 & 0.001 & 643 & 4.01 & 0.9 & 0.002 \\
\hline Others & 349 & $2 \cdot 22$ & $2 \cdot 0$ & & 284 & 7.46 & $5 \cdot 0$ & & 346 & 3.80 & $1 \cdot 1$ & \\
\hline Education** & & & & & & & & & & & & \\
\hline Advanced & 718 & $2 \cdot 47$ & $2 \cdot 0$ & 0.023 & 600 & 8.67 & 4.3 & $<0.001$ & 725 & 4.01 & 0.9 & 0.005 \\
\hline Low & 386 & $2 \cdot 17$ & $2 \cdot 1$ & & 310 & $7 \cdot 19$ & $5 \cdot 2$ & & 386 & 3.82 & $1 \cdot 1$ & \\
\hline Fathers & & & & & & & & & & & & \\
\hline BMI status & & & & & & & & & & & & \\
\hline Normal weight & 327 & $2 \cdot 56$ & $2 \cdot 1$ & 0.046 & 267 & 8.62 & 4.7 & 0.061 & 333 & 3.98 & 1.0 & 0.941 \\
\hline Overweight & 529 & $2 \cdot 27$ & $2 \cdot 1$ & & 443 & 7.94 & 4.7 & & 534 & 3.97 & 0.9 & \\
\hline Working status & & & & & & & & & & & & \\
\hline Working & 984 & $2 \cdot 36$ & $2 \cdot 1$ & 0.675 & 808 & $8 \cdot 11$ & 4.4 & 0.482 & 987 & 3.94 & 1.0 & 0.604 \\
\hline Not working & 115 & 2.45 & $2 \cdot 1$ & & 95 & 8.46 & $6 \cdot 0$ & & 118 & 3.89 & 1.0 & \\
\hline Occupational clas & & & & & & & & & & & & \\
\hline Professionals & 537 & $2 \cdot 45$ & $2 \cdot 1$ & 0.021 & 447 & 8.55 & 4.4 & 0.003 & 543 & 3.98 & 0.9 & 0.032 \\
\hline Others & 368 & $2 \cdot 12$ & $2 \cdot 0$ & & 310 & 7.47 & $5 \cdot 1$ & & 367 & 3.84 & 1.0 & \\
\hline Education & & & & & & & & & & & & \\
\hline Advanced & 520 & 2.56 & $2 \cdot 1$ & 0.002 & 432 & 8.88 & $4 \cdot 1$ & $<0.001$ & 524 & 4.02 & 0.9 & 0.001 \\
\hline Low & 554 & $2 \cdot 17$ & $2 \cdot 0$ & & 455 & 7.45 & $5 \cdot 0$ & & 557 & 3.84 & 1.0 & \\
\hline Children & & & & & & & & & & & & \\
\hline Sex & & & & & & & & & & & & \\
\hline Boys & 574 & $2 \cdot 29$ & $2 \cdot 0$ & 0.239 & 472 & 8.35 & $4 \cdot 8$ & 0.192 & 578 & 3.88 & 1.0 & 0.028 \\
\hline Girls & 543 & 2.44 & $2 \cdot 1$ & & 448 & 7.95 & 4.5 & & 546 & 4.01 & 1.0 & \\
\hline Birth weight & & & & & & & & & & & & \\
\hline$<3000 \mathrm{~g}$ & 154 & 1.92 & 1.9 & 0.004 & 127 & $7 \cdot 27$ & 4.6 & 0.021 & 148 & $3 \cdot 70$ & 0.9 & 0.001 \\
\hline$\geq 3000 \mathrm{~g}$ & 963 & 2.44 & $2 \cdot 1$ & & 793 & 8.29 & 4.6 & & 976 & 3.98 & 1.0 & \\
\hline Gestational age & & & & & & & & & & & & \\
\hline$<37$ weeks & 48 & 1.37 & $2 \cdot 0$ & 0.001 & 38 & $6 \cdot 19$ & 4.6 & 0.014 & 47 & 3.85 & $1 \cdot 1$ & 0.014 \\
\hline$\geq 37$ weeks & 1069 & $2 \cdot 41$ & $2 \cdot 1$ & & 882 & $8 \cdot 24$ & 4.6 & & 1095 & $4 \cdot 22$ & 1.0 & \\
\hline
\end{tabular}

$P$ values from two-sample $t$ tests.

${ }^{*}$ All members of the family related by blood or marriage.

†Aggregation of income of family members: high income, $\geq 3000 € /$ month net; low income, $<3000 € /$ month net.

¥Split according to the mean age of women giving birth in Finland in 2012 (https://www.tilastokeskus.fi/til/synt/2012/synt_2012_2013-04-12_tie_001_en.html). §Measured at child's age of 13 months: normal weight, $\mathrm{BMI}<25.0 \mathrm{~kg} / \mathrm{m}^{2}$; overweight, $\mathrm{BMI} \geq 25 \cdot 0 \mathrm{~kg} / \mathrm{m}^{2}$.

IIAt child's age of 13 months.

IProfessionals (in high positions, e.g. managerial, but also in intermediate positions, such as nurses) $v$. others (blue-collar workers in industry or agriculture and service workers)

${ }^{\star *}$ Advanced education (highest level of vocational training (such as a 4-year programme of a polytechnic institute) or any academic degree (bachelor's, master's, licentiate or doctoral degree)) $v$. lower education.

fathers with poor dietary quality. However, after controlling for confounding variables, paternal dietary quality did not have significant association with EBF duration or the introduction of complementary foods (Table 3). The association between fathers' diet quality and total $\mathrm{BF}$ duration was significant $(F(1,369)=4.33, P=0.038)$. 
Table 2 Duration of exclusive breast-feeding (EBF), total duration of breast-feeding (BF) and age of introduction of complementary foods (CF) by mothers' and fathers' eating behaviours: STEPS longitudinal cohort study ( $n$ 1797)

\begin{tabular}{|c|c|c|c|c|c|c|c|c|c|c|c|c|}
\hline \multirow[b]{2}{*}{ Variable } & \multicolumn{4}{|c|}{ EBF duration (months) } & \multicolumn{4}{|c|}{ Total BF duration (months) } & \multicolumn{4}{|c|}{ Age of introduction CF (months) } \\
\hline & $n$ & Mean & $\mathrm{SD}$ & $P$ & $n$ & Mean & SD & $P$ & $n$ & Mean & SD & $P$ \\
\hline \multicolumn{13}{|c|}{ Mothers' eating behaviour } \\
\hline \\
\hline High & 448 & $2 \cdot 21$ & $2 \cdot 1$ & \multirow[t]{2}{*}{0.029} & 382 & 7.72 & 4.5 & \multirow[t]{2}{*}{0.008} & 446 & 3.84 & 1.0 & \multirow[t]{2}{*}{0.006} \\
\hline Low & 590 & $2 \cdot 49$ & $2 \cdot 0$ & & 471 & 8.58 & $4 \cdot 8$ & & 600 & 4.02 & 1.0 & \\
\hline \multicolumn{13}{|c|}{ Uncontrolled eating* } \\
\hline High & 505 & $2 \cdot 33$ & $2 \cdot 1$ & \multirow[t]{2}{*}{0.511} & 416 & 8.19 & 4.9 & \multirow[t]{2}{*}{$0 \cdot 791$} & 510 & 3.95 & 1.0 & \multirow[t]{2}{*}{0.963} \\
\hline Low & 453 & 2.42 & $2 \cdot 1$ & & 369 & $8 \cdot 28$ & $4 \cdot 6$ & & 456 & 3.96 & 1.0 & \\
\hline \multicolumn{13}{|c|}{ Emotional eating* } \\
\hline High & 425 & $2 \cdot 27$ & $2 \cdot 1$ & \multirow[t]{2}{*}{0.593} & 353 & 8.02 & $4 \cdot 6$ & \multirow[t]{2}{*}{0.948} & 426 & 3.93 & 1.0 & \multirow[t]{2}{*}{$0 \cdot 811$} \\
\hline Low & 427 & $2 \cdot 34$ & $2 \cdot 1$ & & 347 & 8.00 & 4.4 & & 432 & 3.92 & 1.0 & \\
\hline \multicolumn{13}{|c|}{ Food neophobia† } \\
\hline Neophobic & 136 & $2 \cdot 01$ & $2 \cdot 1$ & \multirow[t]{3}{*}{0.002} & 106 & $7 \cdot 23$ & 4.8 & \multirow[t]{3}{*}{0.018} & 168 & 3.95 & $1 \cdot 1$ & \multirow[t]{3}{*}{0.922} \\
\hline Average & 728 & 2.55 & $2 \cdot 0$ & & 610 & 8.48 & 4.7 & & 738 & 3.96 & 1.0 & \\
\hline Neophilic & 167 & $2 \cdot 10$ & $2 \cdot 2$ & & 135 & 8.39 & 3.8 & & 139 & 3.99 & 0.9 & \\
\hline \multicolumn{13}{|c|}{ Dietary quality $\ddagger$} \\
\hline Good & 461 & $2 \cdot 50$ & $2 \cdot 1$ & \multirow[t]{2}{*}{0.124} & 381 & 8.77 & 4.4 & \multirow[t]{2}{*}{0.003} & 464 & 4.03 & 1.0 & \multirow[t]{2}{*}{0.027} \\
\hline Poor & 546 & $2 \cdot 30$ & $2 \cdot 1$ & & 449 & $7 \cdot 81$ & 4.9 & & 554 & 3.90 & 1.0 & \\
\hline Fathers' eating & naviour & & & & & & & & & & & \\
\hline Cognitive res & & & & & & & & & & & & \\
\hline High & 383 & $2 \cdot 37$ & $2 \cdot 1$ & 0.957 & 313 & $8 \cdot 12$ & 4.5 & 0.857 & 385 & 4.00 & 1.0 & 0.209 \\
\hline Low & 441 & $2 \cdot 36$ & $2 \cdot 0$ & & 365 & $8 \cdot 18$ & 4.9 & & 443 & 3.91 & 1.0 & \\
\hline Uncontrolled & ing & & & & & & & & & & & \\
\hline High & 452 & $2 \cdot 36$ & $2 \cdot 1$ & 0.552 & 363 & 8.28 & $4 \cdot 8$ & 0.656 & 454 & 3.95 & 1.0 & 0.887 \\
\hline Low & 422 & 2.45 & $2 \cdot 1$ & & 355 & $8 \cdot 12$ & $4 \cdot 6$ & & 427 & 3.96 & 1.0 & \\
\hline Emotional ea & & & & & & & & & & & & \\
\hline High & 332 & $2 \cdot 38$ & $2 \cdot 2$ & 0.899 & 272 & 8.06 & 4.5 & 0.779 & 338 & 3.96 & 1.0 & 0.951 \\
\hline Low & 457 & 2.40 & $2 \cdot 0$ & & 379 & $8 \cdot 16$ & 4.7 & & 457 & 3.96 & 1.0 & \\
\hline Food neopho & & & & & & & & & & & & \\
\hline Neophobic & 161 & $2 \cdot 12$ & $2 \cdot 1$ & 0.151 & 134 & 7.85 & $5 \cdot 1$ & 0.594 & 131 & 3.97 & $1 \cdot 1$ & 0.758 \\
\hline Average & 607 & 2.40 & $2 \cdot 1$ & & 496 & $8 \cdot 27$ & $4 \cdot 6$ & & 609 & 3.93 & 0.9 & \\
\hline Neophilic & 161 & 2.57 & $2 \cdot 0$ & & 109 & 7.97 & 3.7 & & 168 & 4.00 & 0.9 & \\
\hline Dietary qualit & & & & & & & & & & & & \\
\hline Good & 252 & 2.55 & $2 \cdot 1$ & 0.131 & 205 & 8.84 & 4.4 & 0.011 & 253 & 4.06 & 0.9 & 0.014 \\
\hline Poor & 574 & $2 \cdot 32$ & $2 \cdot 1$ & & 475 & 7.86 & 4.7 & & 581 & 3.89 & 1.0 & \\
\hline
\end{tabular}

$P$ values from two-sample $t$ tests and ANOVA.

${ }^{*}$ Dichotomized at the median split.

†Post hoc tests: average $v$. neophilic, $P<0.05$; average $v$. neophobic, $P<0.05$.

¥Good dietary quality, Index of Diet Quality (IDQ) total score of 10-15 points; poor dietary quality, IDQ score of 0-9 points.

\section{Discussion}

The present study explored the association between mothers' and fathers' eating behaviours and infant-feeding practices. We showed that mothers' restrictive eating behaviour and food neophobia and fathers' dietary quality were associated with BF duration and the age of introduction of complementary foods. Mothers with high levels of food neophobia were more likely to breast-feed exclusively for shorter durations and mothers with high restrictive eating were more likely to introduce solid foods sooner than mothers who scored lower in these behaviours. Also fathers' high diet quality was associated with longer total BF duration. These associations were independent of various demographic characteristics.

In our study, BF and complementary feeding patterns were similar to infant-feeding patterns in Finland in general $^{(6)}$. Both in our sample and in a Finnish nationwide survey, $92 \%$ of infants less than 1 month of age were breastfed, and $43 \%$ and $47 \%$ of infants, respectively, were exclusively breast-fed. At the age of 4 months, BF was more prevalent in our sample: $76 \%$ were still breast-fed compared with $68 \%$ in the nationwide survey. The rate of those exclusively breast-fed was lower in the present study: 19\% compared with $23 \%$. More than a third of infants were still breast-fed at about 1 year of age in the nationwide survey, while the rate in our sample was only $14 \%$. Data on the introduction of complementary foods were not comparable between the present study and the nationwide survey because of differing methods, but they do show a similar tendency, which is a sharp increase in the frequency of starting solid foods between 3 and 5 months of age, most often in the form of vegetable purées.

Women showed more cognitive restraint, uncontrolled eating and emotional eating than men, which is consistent with earlier studies ${ }^{(32,37)}$. Dietary quality was better among mothers than fathers, which may be due to mothers exhibiting more cognitive restraint in eating than fathers. We showed no statistically significant difference between maternal and paternal food neophobia scores, although, in 
Table 3 The association between parental eating behaviours and duration of exclusive breast-feeding (EBF), total duration of breast-feeding (BF) and age of introduction of complementary foods (CF) adjusted by familial, parental and children's background characteristics: STEPS longitudinal cohort study $(n$ 1797)

\begin{tabular}{|c|c|c|c|c|c|c|}
\hline & \multicolumn{2}{|c|}{ EBF duration ( $n$ 432) } & \multicolumn{2}{|c|}{ Total BF duration ( $n$ 370) } & \multicolumn{2}{|c|}{ Age of introduction CF ( $n$ 443) } \\
\hline & $F$ & $P$ & $F$ & $P$ & $F$ & $P$ \\
\hline \multicolumn{7}{|l|}{ Parental eating behaviour } \\
\hline \multicolumn{7}{|l|}{ Mothers } \\
\hline Cognitive restraint ${ }^{\star}$, high & 0.11 & 0.740 & 0.61 & 0.436 & 4.92 & 0.027 \\
\hline Food neophobiat, average & 5.00 & 0.007 & $1 \cdot 19$ & 0.305 & 0.41 & 0.667 \\
\hline Dietary quality $\ddagger$, poor & 0.32 & 0.569 & 0.01 & 0.919 & 0.34 & 0.561 \\
\hline \multicolumn{7}{|l|}{ Fathers } \\
\hline Dietary quality, poor & 0.04 & 0.845 & 4.33 & 0.038 & 1.38 & 0.241 \\
\hline \multicolumn{7}{|l|}{ Background characteristics } \\
\hline Marital status, married & 0.38 & 0.540 & 0.02 & 0.893 & 0.30 & 0.582 \\
\hline Biological family & 3.75 & 0.054 & $2 \cdot 27$ & 0.133 & $2 \cdot 63$ & 0.105 \\
\hline Number of children, $\geq 2$ & $11 \cdot 31$ & $<0.001$ & 3.03 & 0.083 & $10 \cdot 24$ & 0.002 \\
\hline \multicolumn{7}{|l|}{ Mothers } \\
\hline Age, $\geq 30.3$ years & 0.10 & 0.748 & $0 \cdot 19$ & 0.665 & 0.01 & 0.910 \\
\hline BMI status, overweight & 4.65 & 0.032 & 3.99 & 0.046 & $5 \cdot 26$ & 0.023 \\
\hline Occupational class, professionals & 0.13 & 0.722 & 1.60 & 0.207 & 1.08 & 0.300 \\
\hline Education, advanced & 0.01 & 0.936 & 0.75 & 0.387 & 4.14 & 0.043 \\
\hline \multicolumn{7}{|l|}{ Fathers } \\
\hline BMI status, overweight & 0.97 & 0.326 & 0.48 & 0.490 & 0.00 & 0.986 \\
\hline Occupational class, professionals & 0.00 & 0.946 & 0.17 & 0.676 & 0.00 & 0.978 \\
\hline Education, advanced & 0.26 & 0.614 & 0.88 & 0.349 & 0.10 & 0.755 \\
\hline \multicolumn{7}{|l|}{ Children } \\
\hline Gestational age, premature & 8.75 & 0.003 & 7.36 & 0.007 & 3.38 & 0.066 \\
\hline
\end{tabular}

$P$ values from ANOVA.

${ }^{*}$ Dichotomized at the median split.

†Post hoc tests: average $v$. neophilic, $P<0.05$; average $v$. neophobic, $P<0.05$

¥Good dietary quality, Index of Diet Quality (IDQ) total score of 10-15 points; poor dietary quality, IDQ score of 0-9 points.

some studies, men have been shown to be significantly more neophobic than women ${ }^{(35,38)}$.

Higher maternal cognitive restraint in eating was associated with shorter exclusive BF duration and earlier introduction of complementary foods. The latter association was still apparent after adjusting the analysis for possible confounding factors. Parentally restrained eating has been associated with BMI and body dissatisfaction and has been widely studied as a factor contributing to overweight and obesity in children through child-feeding behaviours ${ }^{(39-42)}$. However, to our knowledge, only one study has focused on early infant-feeding practices ${ }^{(15)}$. Studies suggest that restrictive eating in parents predicts restrictive feeding, which may negatively affect a child's eating behaviour by increasing the preference for palatable foods, thus increasing intake and weight ${ }^{(43,44)}$. However, the results are conflicting. An earlier study linked mothers' dietary restraint to healthier food choices for their children ${ }^{(45)}$. In infancy, due to the infant-led nature of $\mathrm{BF}$, parents who want to control their children's eating may choose to feed infants formula from birth or to stop BF earlier to make feeding easier to control $^{(15,27,46)}$. The same mechanism may apply to the early initiation of complementary foods; however, the reasons behind our finding that a mother's cognitive restraint is negatively associated with $\mathrm{BF}$ duration and the initiation of complementary foods must be further elucidated. In our study sample, uncontrolled or emotional eating behaviours in parents did not have significant associations with child- feeding practices, although this could have been assumed based on earlier studies conducted with older children ${ }^{(47,48)}$.

Mothers' food neophobia was associated with BF duration. The longest BF duration was among mothers who were considered average, according to their FNS scores. There was a statistically significant difference between average and neophobic mothers with regard to exclusive $\mathrm{BF}$ and total $\mathrm{BF}$ duration. The difference in exclusive $\mathrm{BF}$ duration also appeared in the adjusted analysis. Previous studies examining the association between parental food neophobia and child feeding have been conducted with older children, and a recent study found an association between maternal neophobia and restriction on one hand and children's weight and poor child-feeding practices on the other ${ }^{(16)}$. The results of that study suggest that maternal neophobia is inversely related to healthy feeding, which is consistent with our study. It is unknown why neophilic mothers' child-feeding practices tended to be worse than those of average mothers and further studies are needed on this subject.

Fathers significantly influence infant-feeding practices, although mothers certainly have a greater influence on early child feeding. The father's role in BF has been widely studied. His knowledge of the benefits of $\mathrm{BF}$ is associated with the initiation and duration of $\mathrm{BF}^{(49,50)}$. Moreover, a mother who believes her spouse has positive attitudes towards $\mathrm{BF}$ is more likely to initiate and continue $\mathrm{BF}^{(51)}$. In our study, the fathers' eating behaviours (measured with TFEQ and FNS) were not significantly associated with 
child-feeding practices, but there was an association between the mothers' and fathers' dietary qualities and child-feeding practices. The high diet quality of both fathers and mothers was associated with longer BF duration and the later introduction of complementary foods in unadjusted analyses. Interestingly, when confounding factors were considered, an association between the dietary quality of fathers, but not mothers, and total BF duration remained statistically significant. The father's poor eating practices may relate to his attitude towards BF and, thus, the support he provides to the mother. In other studies, the mother's good eating habits have been linked to longer durations of $\mathrm{BF}$ and better adherence to infant-feeding guidelines ${ }^{(52)}$, but no studies are available on the possible links between a father's diet and infant-feeding practices.

The present study has many strengths. In our study, multiple methods were used to assess parental eating behaviours and practices. Moreover, we collected data from both mothers and fathers, whereas many studies lack data on fathers. In addition, our analyses were based on longitudinal prospective data on infants' and young children's feeding across multiple indicators. Earlier research on the subject being scant, the current study expands the existing knowledge on the topic.

Despite these strengths, the study also has a few limitations. In our study, we wanted to discover how parental eating behaviours affect infant and young child feeding practices, but the data on parental eating behaviours were, in some cases, collected after the data on child feeding. The TFEQ was collected when infants were 4 months of age, and the FNS and IDQ were collected at 13 months. At 4 months, most infants were no longer fully breast-fed and had already started solid foods; and by 13 months, most mothers had stopped breast-feeding. According to previous studies, food neophobia has been found to be fairly stable at the age range of the parents in our study ${ }^{(35,53)}$. Research on the effects of age or pregnancy on factors measured with TFEQ is sparse. However, there exists a small study that also suggests that mothers' dietary restraints do not change significantly from the prenatal to the postnatal period ${ }^{(54)}$. That study implies that parents' eating behaviours may be fairly stable. Another limitation of the present study was the use of parental reports through follow-up diaries to determine exclusive $\mathrm{BF}$, total $\mathrm{BF}$ duration and the date of introduction of complementary foods. Parental reporting is a frequently used method, but its reliability and validity in studying infantfeeding practices have been questioned in some studies, especially when data are collected retrospectively ${ }^{(55,56)}$. In our study, the parents were instructed to fill in their data in real time, but it is not known whether the parents followed these instructions.

\section{Conclusion}

In conclusion, maternal restrictive eating and food neophobia and paternal dietary quality were associated with feeding practices for infants and young children. Gaining an understanding of the influences of parents' eating behaviours on $\mathrm{BF}$ and complementary feeding is important for informing clinical efforts about how to improve infantfeeding practices. More research is needed on the associations between parental eating behaviours and child feeding, as well as on eating behaviours later in childhood. Another unanswered question is whether parents' eating behaviours can predict a child's later health outcomes, such as whether he or she becomes overweight or obese. Because relationships, social networks and infant-feeding cultures can be different among nations, a generalization of these results to other countries should be approached with caution.

\section{Acknowledgements}

Acknowledgements: The authors are grateful to all the families who took part in the study, the midwives for their help in recruiting them and the whole STEPS study team. Financial support: The main funding for the STEPS study comes from the University of Turku, Abo Akademi University and the Turku University Hospital. The present research was specifically funded by the Academy of Finland (grant number 121569); the Juho Vainio Foundation; and the Finnish Cultural Foundation, Varsinais-Suomi Regional Fund. The aforementioned sponsors had no role in the design, analysis or writing of this article. Conflict of interest: None. Authorship: H.L., H.N., M.A. and J.V. were responsible for the design of the study, J.V. for data collection. A.K. was responsible for statistical analyses. J.V. wrote the manuscript. All authors contributed to the data analysis and writing and revising the manuscript and approved the final draft. Ethics of buman subject participation: This study was conducted according to the guidelines laid down in the Declaration of Helsinki and all procedures involving human subjects were approved by the Ministry of Social Affairs and Health Ethics and the Committee of the Hospital District of Southwest Finland (2007-02-27). Written informed consent was obtained from all participants and they were informed of their right to withdraw from the study at any point.

\section{References}

1. World Health Organization \& UNICEF (2003) Global Strategy for Infant and Young Child Feeding. Geneva: WHO; available at http://www.who.int/entity/nutrition/publications/ infantfeeding/9241562218/en/index.html

2. European Food Safety Authority, Panel on Dietetic Products Nutrition and Allergies (2009) Scientific Opinion on the appropriate age for introduction of complementary feeding of infants. EFSA J 7, 1423.

3. American Academy of Pediatrics (2012) Breastfeeding and the use of human milk. Pediatrics 129, e827-e841.

4. Schiess S, Grote V, Scaglioni S et al. (2010) Introduction of complementary feeding in 5 European countries. J Pediatr Gastroenterol Nutr 50, 92-98. 
5. Arabi M, Frongillo EA, Avula R et al. (2012) Infant and young child feeding in developing countries. Child Dev $\mathbf{8 3}$, $32-45$.

6. Uusitalo L, Nyberg H, Pelkonen M et al. (2012) Infant Feeding in Finland 2010 (Imeväisikäisten ruokinta Suomessa 2010). Report no. 8. Helsinki: National Institute for Health and Welfare.

7. Erkkola M, Salmenhaara M, Kronberg-Kippila C et al. (2010) Determinants of breast-feeding in a Finnish birth cohort. Public Health Nutr 13, 504-513.

8. de Jager E, Broadbent J, Fuller-Tyszkiewicz $\mathrm{M}$ et al. (2014) The role of psychosocial factors in exclusive breastfeeding to six months postpartum. Midwifery 30 , 657-666.

9. Andren Aronsson C, Uusitalo U, Vehik K et al. (2013) Age at first introduction to complementary foods is associated with sociodemographic factors in children with increased genetic risk of developing type 1 diabetes. Matern Child Nutr (Epublication ahead of print version).

10. Tromp II, Briede S, Kiefte-de Jong JC et al. (2013) Factors associated with the timing of introduction of complementary feeding: the Generation R Study. Eur J Clin Nutr 67, 625-630.

11. Erkkola M, Salmenhaara M, Nwaru BI et al. (2013) Sociodemographic determinants of early weaning: a Finnish birth cohort study in infants with human leucocyte antigenconferred susceptibility to type 1 diabetes. Public Health Nutr 16, 296-304

12. Grote V, Schiess SA, Closa-Monasterolo R et al. (2011) The introduction of solid food and growth in the first $2 \mathrm{y}$ of life in formula-fed children: analysis of data from a European cohort study. Am J Clin Nutr 94, 6 Suppl., 1785S-1793S.

13. Hoffman ER, Zerwas SC \& Bulik CM (2011) Reproductive issues in anorexia nervosa. Expert Rev Obstet Gynecol 6, 403-414.

14. Patel P, Wheatcroft R, Park RJ et al. (2002) The children of mothers with eating disorders. Clin Child Fam Psychol Rev 5, 1-19.

15. Brown A (2014) Maternal restraint and external eating behaviour are associated with formula use or shorter breastfeeding duration. Appetite 76, 30-35.

16. Tan CC \& Holub SC (2012) Maternal feeding practices associated with food neophobia. Appetite 59, 483-487.

17. Galloway AT, Lee Y \& Birch LL (2003) Predictors and consequences of food neophobia and pickiness in young girls. J Am Diet Assoc 103, 692-698.

18. Lee SY, Hoerr SL \& Schiffman RF (2005) Screening for infants' and toddlers' dietary quality through maternal diet. MCN Am J Matern Child Nurs 30, 60-66.

19. Amir LH \& Donath S (2007) A systematic review of maternal obesity and breastfeeding intention, initiation and duration. BMC Pregnancy Childbirth 7, 9.

20. Robinson S, Marriott L, Poole J et al. (2007) Dietary patterns in infancy: the importance of maternal and family influences on feeding practice. Br J Nutr 98, 1029-1037.

21. Bar-Yam NB \& Darby L (1997) Fathers and breastfeeding: a review of the literature. J Hum Lact 13, 45-50.

22. Wasser HM, Thompson AL, Siega-Riz AM et al. (2013) Who's feeding baby? Non-maternal involvement in feeding and its association with dietary intakes among infants and toddlers. Appetite 71, 7-15.

23. Oliveria SA, Ellison RC, Moore LL et al. (1992) Parent-child relationships in nutrient intake: the Framingham Children's Study. Am J Clin Nutr 56, 593-598.

24. Thorsdottir I, Gunnarsdottir I, Ingolfsdottir SE et al. (2006) Fruit and vegetable intake: vitamin $C$ and $\beta$-carotene intake and serum concentrations in six-year-old children and their parents. Scand J Food Nutr 50, 71-76.
25. Hall L, Collins CE, Morgan PJ et al. (2011) Children's intake of fruit and selected energy-dense nutrient-poor foods is associated with fathers' intake. J Am Diet Assoc 111, 1039-1044.

26. Shrivastava A, Murrin C, Sweeney MR et al. (2013) Familial intergenerational and maternal aggregation patterns in nutrient intakes in the Lifeways Cross-Generation Cohort Study. Public Health Nutr 16, 1476-1486.

27. Brown A \& Lee M (2013) Breastfeeding is associated with a maternal feeding style low in control from birth. PLoS One 8, e 54229 .

28. Lagström H, Rautava P, Kaljonen A et al. (2012) Cohort profile: Steps to the Healthy Development and Wellbeing of Children (the STEPS Study). Int J Epidemiol 42, 1273-1284.

29. Karlsson J, Persson LO, Sjöström L et al. (2000) Psychometric properties and factor structure of the Three-Factor Eating Questionnaire (TFEQ) in obese men and women. Results from the Swedish Obese Subjects (SOS) study. Int J Obes Relat Metab Disord 24, 1715-1725.

30. Pliner P \& Hobden K (1992) Development of a scale to measure the trait of food neophobia in humans. Appetite 19, 105-120.

31. Leppälä J, Lagström H, Kaljonen A et al. (2010) Construction and evaluation of a self-contained index for assessment of diet quality. Scand J Public Health 38, 794-802.

32. Anglé S, Engblom J, Eriksson T et al. (2009) Three factor eating questionnaire-R18 as a measure of cognitive restraint, uncontrolled eating and emotional eating in a sample of young Finnish females. Int J Behav Nutr Phys Act 6, 41 .

33. de Lauzon B, Romon M, Deschamps V et al. (2004) The Three-Factor Eating Questionnaire-R18 is able to distinguish among different eating patterns in a general population. J Nutr 134, 2372-2380.

34. Porter KN \& Johnson MA (2011) Obesity is more strongly associated with inappropriate eating behaviors than with mental health in older adults receiving congregate meals. J Nutr Gerontol Geriatr 30, 403-415.

35. Tuorila H, Lähteenmäki L, Pohjalainen L et al. (2001) Food neophobia among the Finns and related responses to familiar and unfamiliar foods. Food Qual Prefer 12, 29-37.

36. Falciglia GA, Couch SC, Gribble LS et al. (2000) Food neophobia in childhood affects dietary variety. J Am Diet Assoc 100, 1474-1481.

37. Keskitalo K, Tuorila H, Spector TD et al. (2008) The ThreeFactor Eating Questionnaire, body mass index, and responses to sweet and salty fatty foods: a twin study of genetic and environmental associations. Am J Clin Nutr 88, 263-271.

38. Hursti UkK \& Sjoden P (1997) Food and general neophobia and their relationship with self-reported food choice: familial resemblance in Swedish families with children of ages 7-17 years. Appetite 29, 89-103.

39. Rodgers RF, Paxton SJ, McLean SA et al. (2013) Do maternal body dissatisfaction and dietary restraint predict weight gain in young pre-school children? A 1-year follow-up study. Appetite 67, 30-36.

40. Birch LL \& Fisher JO (2000) Mothers' child-feeding practices influence daughters' eating and weight. Am J Clin Nutr $\mathbf{7 1}$, 1054-1061.

41. Farrow CV \& Blissett J (2009) Do obsessive compulsive symptoms mediate the relationship between maternal eating psychopathology and restrictive feeding practices? Int J Eat Disord 42, 76-80.

42. Hood MY, Moore LL, Sundarajan-Ramamurti A et al. (2000) Parental eating attitudes and the development of obesity in children. The Framingham Children's Study. Int J Obes Relat Metab Disord 24, 1319-1325.

43. Johannsen DL, Johannsen NM \& Specker BL (2006) Influence of parents' eating behaviors and child feeding 
practices on children's weight status. Obesity (Silver Spring) 14, 431-439.

44. Bartok CJ \& Ventura AK (2009) Mechanisms underlying the association between breastfeeding and obesity. Int J Pediatr Obes 4, 196-204.

45. Contento IR, Zybert P \& Williams SS (2005) Relationship of cognitive restraint of eating and disinhibition to the quality of food choices of Latina women and their young children. Prev Med 40, 326-336.

46. Brown A, Raynor P \& Lee M (2011) Maternal control of child-feeding during breast and formula feeding in the first 6 months post-partum. J Hum Nutr Diet 24, 177-186.

47. Kröller K, Jahnke D \& Warschburger P (2013) Are maternal weight, eating and feeding practices associated with emotional eating in childhood? Appetite 65, 25-30.

48. Wardle J, Sanderson S, Guthrie CA et al. (2002) Parental feeding style and the inter-generational transmission of obesity risk. Obes Res 10, 453-462.

49. Pisacane A, Continisio GI, Aldinucci M et al. (2005) A controlled trial of the father's role in breastfeeding promotion. Pediatrics 116, e494-e 498.
50. Susin LR \& Giugliani ER (2008) Inclusion of fathers in an intervention to promote breastfeeding: impact on breastfeeding rates. J Hum Lact 24, 386-392.

51. Scott JA, Binns CW \& Aroni RA (1997) The influence of reported paternal attitudes on the decision to breast-feed. J Paediatr Child Health 33, 305-307.

52. Leslie DA, Hesketh KD \& Campbell KJ (2012) Breastfeeding mothers consume more vegetables and a greater variety of fruits and vegetables than non-breastfeeding peers: the influence of socioeconomic position. Nutr Diet 69, 84-90.

53. McFarlane T \& Pliner P (1997) Increasing willingness to taste novel foods: effects of nutrition and taste information. Appetite 28, 227-238.

54. Stein A \& Fairburn CG (1996) Eating habits and attitudes in the postpartum period. Psychosom Med 58, 321-325.

55. Coit J, Grossman X, Buczek M et al. (2012) Introducing solid foods: validity of report among mothers who do not adhere to recommended US guidelines. J Hum Lact 28, 490-494.

56. Li R, Scanlon KS \& Serdula MK (2005) The validity and reliability of maternal recall of breastfeeding practice. Nutr Rev 63, 103-110. 